\title{
Improving morbidity and mortality in intensive care through learning from deaths, and the role of the Structured Judgement Review (SJR) methodology in this process
}

\author{
Erandhi Malika Siriwardena ${ }^{{ }^{*}}$ \\ Consultant in Anaesthesia and Intensive Care Medicine, Northern Lincolnshire and Goole NHS \\ Foundation Trust, United Kingdom.
}

\begin{abstract}
Learning from deaths occurring in intensive care has been given much focus in the recent years in clinical governance processes in order to improve morbidity and mortality in critically ill patients. When mistakes happen, providers need to understand individual as well as system failures and take necessary steps to avoid recurrences of shortcomings. This involves a well-defined response to deaths including a robust system to review deaths as well as parallel governance processes to reinforce lessons learnt.
\end{abstract}

The Structured Judgement Review (SJR) methodology is being introduced in the UK as a tool for standardising and quantifying analysis of the problems in the care of patients that have died in the ITU. It can be restricted to patients who were expected to survive, and so focus resources into searching for systematic failings of the unit where they are most likely to have occurred. The SJR uses local reviewers to review case notes against a series of specific enquiries and then requires them to score the quality of care against a scale for each criterion.

This review is then used to link back to education and focusing of resources within the hospital's ITU and parent teams.

Keywords: Intensive care; learning from deaths; mortality reviews; structured judgement reviews; clinical governance; quality improvement

\section{Introduction}

Patient safety is a major concern in all healthcare systems. Based on studies across the world, it is estimated that as many as one in 10 patients admitted to hospital in a developed country will be the victim of an unintentional error, and up to $50 \%$ of these are preventable. ${ }^{1-3}$ In recent years, there has also been an increasing international interest in using mortality rates and morbidity and mortality data to monitor the quality of hospital care. $^{4,5}$

Learning from deaths was brought forward by the Care Quality Commission in the United Kingdom in 2016 because it was found that learning from deaths were not being given sufficient priority,

*Correspondence: Erandhi Malika Siriwardena

E mail: emsiriwardena@yahoo.com

https://orcid.org/0000-0003-3124-641X

DOI: http://doi.org/10.4038/slja.v27i2.8473

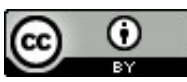

and consequently, valuable opportunities for improvements were being missed. 6,7

When mistakes happen, providers can use this to understand the causes. The purpose of a review of deaths is to find which problems in care might have contributed, and to learn from them in order to prevent recurrence. Reviews and investigations are only useful for learning purposes if their findings are shared and acted upon. This is where morbidity and mortality meetings and other clinical governance processes play a key role.

\section{The Process of Learning from deaths in Intensive Care}

\section{Responding to Deaths}

There should be a policy in place in each intensive care unit that sets out how it responds to the deaths of patients under its care. The primary goal of the process is to improve healthcare quality through qualitative analysis of mortality data, using a standardized, validated approach linked to quality improvement activity. 
There are three levels of scrutiny that a provider can apply to the care provided to someone who dies as set out in the guidance by NHS England in $2017 .^{6}$

1. Death certification - Deaths by natural causes are certified by the attending doctor. Doctors are encouraged to report any death to the coroner that they cannot readily certify as being due to natural causes.

2. An investigation - Providers may decide that some deaths warrant an investigation as there has been an occurrence of a serious incident.

3. Case record review - Some deaths should be subject to further review by the provider, looking at the care provided to the deceased as recorded in their case records in order to identify any learning and areas for improvement.

In the UK and most other countries carrying out mortality reviews, it is generally accepted and recommended that all deaths in patients with a learning disability, those with a serious mental health illness, those aged under 18 years and all perinatal and maternal deaths need to be reviewed. Additionally, it is also advised that hospitals review all deaths where family or staff have raised concerns. Where the patient was not expected to die, for example an elective procedure, and where the lessons will inform a provider's quality improvement work (e.g. end of life care) ${ }^{8}$, the Structured Judgment Review (SJR) of case notes, is a method being advocated by the Royal College of Physicians. ${ }^{6}$ Other methodologies exist, but hospitals need to be assured that the structure they are using is robust and evidence-based, and that it will generate the information they are now being required to publish. The staff must be trained, given sufficient time to undertake case record reviews, and then resources to act on what they learn.

From a practical point of view, it may not be feasible to review all deaths occurring in a particular intensive care unit. This holds true in particular for larger units with higher bed strength and significant turnover of patients. While it remains important to review all deaths that fall in to any of the criteria specified above, it is recommended to use a mortality prediction tool or scoring system to screen the other deaths in an attempt to identify those that require a formal review. A commonly used score in ITUs in the
UK for the case selection process is the ICNARC score.

\section{Governance process}

Any process that can potentially reveal harm must include parallel governance processes. The possible outcomes of this could be:

a. To reveal problems within the healthcare processes in the intensive care units. These are system failures.

b. Identification of aspects of poor care delivered by individual clinicians or teams.

The governance activities linked to the learning from deaths process in the ITU setting include-

i. Feedback to individual specialists, respective teams or whole divisions to improve their policies and practice.

ii. Link to morbidity and mortality meetings to cascade learning points to the intensive care team and relevant parent teams.

iii. Link to quality improvement / patient safety teams to implement changes at an institutional level.

iv. Link to serious incidents reviews / root cause analysis studies to change unsafe practices and policies within the unit.

v. Hospital reports targeting organizational level changes.

vi. National reports targeting national level changes.

\section{Structured Judgment Methodology (SJR) as a Tool to Review Deaths}

SJR is a standardized, yet not rigid, case notes review methodology which can be used across services, teams and specialties. The objective of the review method is to look for strengths and weaknesses in the caring process, to provide information about what can be learnt about the hospital systems where care goes well, and to identify points where there may be gaps, problems or difficulty in the care process. ${ }^{8}$

SJR blends traditional, clinical judgment based, review methods with a standard format. ${ }^{8}$ This approach requires reviewers to make safety and quality judgments over successive phases of care, to make explicit written comments about the care given in each phase, and to score care for each phase. ${ }^{9,10}$ 


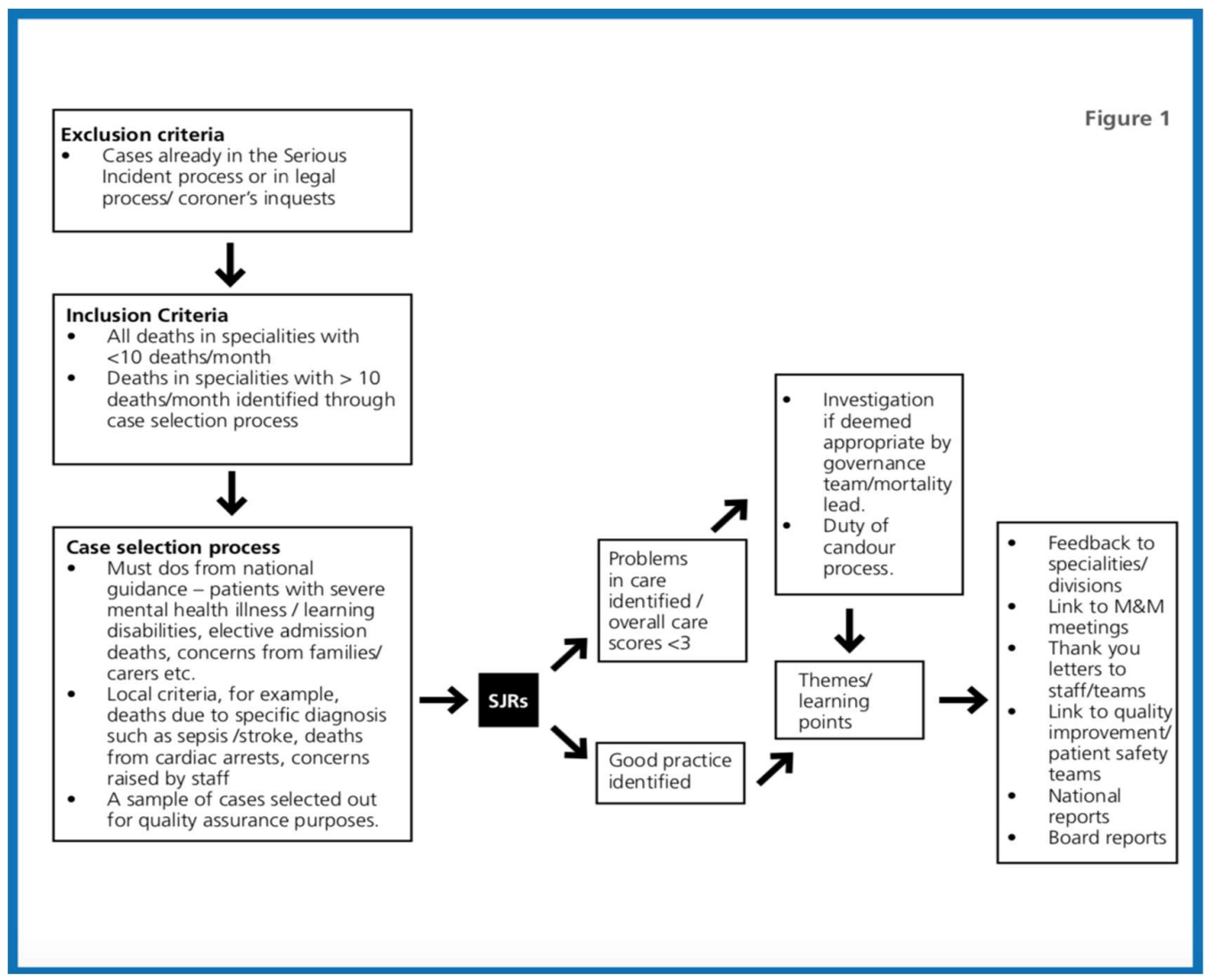

There are two stages to the review process. The first stage is mainly the domain of what might be called 'front line' reviewers, who are trained in the method and who undertake reviews within their own services or directorates. A second stage review is recommended where significant problems or errors have been identified by a first stage reviewer, and an overall poor care score has been given.

\footnotetext{
Box 1 - Phases of care assessed

- Admission and initial care - first 24 hours

- Ongoing care

- Care during a procedure

- Perioperative / procedure care

- End-of-life care (or discharge care)

- Assessment of care overall
}

Explicit judgment comments related to each of the above phases are the core of the method. The purpose of the review is to provide information from which the multidisciplinary teams in ITU or sometimes the organization can learn. Explicit judgment commentaries serve two main purposes. First, they allow the reviewer to concisely describe how and why they assessed the safety and quality of care provided. Second, they provide a commentary that other health professionals can readily understand if they subsequently look at the completed review. ${ }^{9}$

Care scores are recorded after the judgment comments have been written, and the score is in itself the result of a judgment by the reviewer. Only one score is given per phase of care: it is not necessary to score each judgment statement.

\section{Box 2 - Examples of explicit structured judgement comments}

- Continued omission to provide oxygen and respiratory support - poor care.

- Team failed to discuss potential diagnosis with patient - unsatisfactory.

- $\quad$ Referral to intensive treatment unit (ITU) was too late.

- Very good care - rapid triage and identification of diabetic ketoacidosis with appropriate treatment.

These scores have a number of uses. For the individual reviewer, scores help them to come to a rounded judgment on the phase of care particularly when there may be a mix of good and 


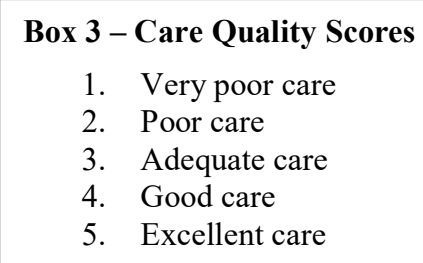

unsatisfactory care within a phase. The reviewer must judge what their overall decision is about the care provided for each phase and for care overall. ${ }^{9,10}$ Scoring makes this very explicit.

Whilst the explicit judgment comments and care scoring are the main two elements of an SJR, reviewers will subsequently be asked to make an assessment of problems in healthcare. The reviewers are expected to identify types of problems given in Box 4 and, if so, identify if it led to harm.

\section{Box 4 - Problem types in health care}

1. Problem in assessment, investigation or diagnosis

2. Problem with medication / IV fluids / electrolytes / oxygen (other than anaesthetic)

3. Problem related to treatment and management plans

4. Problem with infection management.

5. Problem related to operative/ invasive procedure (other than infection control).

6. Problem in resuscitation following a cardiac or respiratory arrest

7. Problem in clinical monitoring (including failure to plan, to undertake, or to recognize and respond to changes).

8. Problem of any other type not fitting the categories above including communication and organizational issues.

The final stage of the SJR process is to judge the avoidability of the death. This is achieved by using a six-point avoidability scale given below $^{11,12}$;

\section{Box 5 - Avoidability of death scale}

1. Definitely avoidable

2. Strong evidence of avoidability

3. Probably avoidable (more than 50:50)

4. Possibly avoidable, but not very likely (less than 50:50)

5. Slight evidence of avoidability

6. Definitely not avoidable
In conclusion the entire process of mortality review, data gathering and the governance processes that needs to follow is time and labour intensifying. A simple time-based longitudinal sample of around 40-50 cases will produce a rich source of quantitative and qualitative information on what goes right and what is not working properly. Timely review, rather than review after a delay, provides better information. ${ }^{9,10}$ The information gathered allows for themes to be developed that then allows a focus for the next improvement steps. Such an approach also has the benefit of enabling individuals to learn from and be satisfied with the cases where care has gone well.

\section{References}

1. Neale G, Woloshynowych M Retrospective case record review: a blunt instrument that needs sharpening. Quality and Safety in Health Care 2003; 12: 2-3

https://doi.org/10.1136/qhc. 12.1 .2 PMid:12571333 PMCid:PMC1743669

2. Baker RG, Norton PG, Flintoft V, et al. The Canadian Adverse Events Study: the incidence of adverse events among hospital patients in Canada. Canad Med Assoc J 2004;170:1678-86 https://doi.org/10.1503/cmaj.1040498 PMid:15159366 PMCid:PMC408508

3. Thomas EJ, Studdert DM, Burstin HR, et al. Incidence and types of adverse events and negligent care in Utah and Colorado. Med Care 2000;38:261-71

https://doi.org/10.1097/00005650-200003000$\underline{00003}$

PMid:10718351

4. The Canadian Institute for Health Information. HSMR: A New Approach for Measuring Hospital Mortality Trends in Canada. Ottawa: CIHI, 2007.

5. Jarman B, Pieter D, Van der Veen AA, et al. The hospital standardised mortality ratio: a powerful tool for Dutch hospitals to assess their quality of care? Qual Safe Health Care 2010; 19:9 - 13. https://doi.org/10.1136/qshc.2009.032953 PMid:20172876 PMCid:PMC2921266

6. National Quality Board. National Guidance on Learning from Death: A Framework for NHS Trusts and NHS Foundation Trusts on identifying, reporting, investigating and learning from deaths in care. March 2017. www.england.nhs.uk/wpcontent/ uploads/2017/03/nqb-national-guidancelearning-from- deaths.pdf

7. Care Quality Commission. Learning, candour and accountability. A review of the way NHS trusts review and investigate the deaths of patients in England. 2016.

www.cqc.org.uk/sites/default/files/20161213learning-candour-accountability-full-report.pdf 
8. Royal College of Physicians. Using the structured judgement review method - a clinical governance guide to mortality case record reviews. London: RCP, 2016.

9. Hutchinson A. Using the structured judgement review method - a guide to reviewers 2017. Royal College of Physicians - National mortality Review Programme.

10. Hutchinson A, Coster JE, Cooper KL, Pearson M, McIntosh A, Bath PA. A structured judgement method to enhance mortality case note review: development and evaluation. BMJ Quality and Safety 2013;22:1032- 1040.

https://doi.org/10.1136/bmjqs-2013-001839 PMid:23868866

11. Hogan H, Zipfel R, Neuberger J, Hutchings A, Darzi A, Black N. Avoidability of hospital deaths and association with hospital-wide mortality ratios: retrospective case record review and regression analysis. BMJ 2015;351:h3239. https://doi.org/10.1136/bmj.h3239

PMid:26174149 PMCid:PMC4502415

12. Olanrewaju O S, Weerasinghe $\mathrm{C}$, Brown $\mathrm{R}$. Preventable hospital mortality: learning from retrospective case record review. Journal of the Royal Society of Short Reports 2012 Nov; 3 (11): 77.

https://doi.org/10.1258/shorts.2012.012077

PMid:23323195 PMCid:PMC3545333

13. Harrison DA, Ferrando Vivas P, Shahin J, Rowan KM. Ensuring comparisons of health-care providers are fair: development and validation of risk prediction models for critically ill patients. Health ServDeliv Res 2015; 3(41).

https://doi.org/10.3310/hsdr03410 PMid:26491757

14. Harrison DA, Parry GJ, Carpenter JR, Short A, Rowan K. A new risk prediction model for critical care: the Intensive Care National Audit \& Research Centre (ICNARC) model. Crit Care Med 2007; 35:1091-8.

https://doi.org/10.1097/01.CCM.0000259468.245 32.44

PMid: 17334248 